\title{
Demonstratives can train spatial perspective taking: The case of Spanish
}

\author{
Paula Rubio-Fernandez \\ Department of Philosophy, University of Oslo \\ Department of Brain and Cognitive Science, MIT
}

\begin{abstract}
Demonstratives are used in all the world's languages to establish joint attention between interlocutors. I have recently proposed that demonstratives further train speakers of different languages in spatial perspective taking by automatizing the computation of different relational values (e.g., the distance, familiarity or altitude of a referent) from different perspectives (the speaker's, the listener's or both) depending on the language. The present study starts by pointing out a common mis-analysis of the form 'este' in Spanish as a proximal demonstrative, when it is in fact used as a filler. I then report an online study $(\mathrm{N}=51)$ testing two alternative views of the Spanish demonstrative system: the distance-oriented view (according to which all Spanish demonstratives indicate relative distance from the speaker) vs the person-oriented view (according to which the proximal forms indicate proximity to the speaker, the medial forms indicate proximity to the listener and the distal forms indicate distance from both speaker and listener). The results of the study confirmed the personoriented account, supporting the view that there is a fundamental distinction between near and far space in demonstrative use, with interactive factors (such as listener position) playing a role in far space.
\end{abstract}

Keywords: demonstratives; joint attention; spatial perspective taking; peripersonal space; social cognition.

Demonstratives (words like 'this' and 'that' in English) are also known as directives because they are used to orient the listener's attention towards an element in the speech situation, either physical (e.g., 'I prefer this one') or discoursive ('That was a good year'). Diessel (1999; 2003; 2012a, 2012b) has shown that demonstratives serve two closely related functions: they indicate the spatial location of a referent relative to the deictic center (e.g., the speaker's position in English), and they coordinate the interlocutors' joint focus of attention. Diessel argues that coordinating speaker-listener joint attention is one of the most basic functions of language, which also links demonstratives to social cognition. Building on extensive typological work by Diessel $(1999,2006)$ and Evans and colleagues (2018a, 2018b; Bergqvist \& Knuchel, 2019), I have recently argued that demonstratives are a lynchpin for the development of social cognition, training young children in spatial perspective taking (RubioFernandez, 2020).

According to the positive feedback loop hypothesis, language and social cognition coevolved in diachrony and co-develop in ontogeny through the acquisition and regular use of pragmatic forms such as demonstratives. This proposal rests on four key features of demonstratives (Rubio-Fernandez, 2020): 
1. Demonstratives are universal: they occur in all of the world's languages (Levinson, 2018).

2. Demonstratives are often accompanied by a pointing gesture, which is also a universal communicative device to establish joint attention (Kita, 2003).

3. Demonstratives emerge very early in language acquisition (Clark, 1978).

4. Demonstratives are so old, etymologically, that their roots cannot be traced back to other types of expressions. This suggests that demonstratives emerged very early in the evolution of language, probably because of their basic communicative function to coordinate the interlocutors' joint attention (Diessel, 2003).

While demonstratives are universal, their meaning varies cross-linguistically. Thus, depending on the language, demonstratives may indicate not only the distance, but also the altitude, familiarity, position, reachability or visibility of a referent, from the perspective of the speaker, the listener, or both. Since demonstratives encode different relational values and require shifting perspectives, I hypothesized that their acquisition should help the development not only of early joint attention, but also of spatial perspective taking (RubioFernandez, 2020). This hypothesis lends itself to the prediction of cross-linguistic differences in social cognition development: the acquisition of perspective taking follows different paths depending on the relational values and perspectives encoded in the demonstrative system(s) that the child is learning. From a mature perspective, adult speakers of different languages would have automatized different forms of spatial perspective taking (e.g., the calculation of a referent's altitude or its visibility to the listener) depending on the relational values and perspectives encoded in their demonstrative system.

A humble first step towards testing these broad hypotheses, the present study investigated the use of demonstratives by adult native speakers of Spanish. Unlike English, the Spanish system distinguishes three forms: proximal ('este'), medial ('ese') and distal ('aquel') demonstratives (for the full class, see Table 1). Japanese, another language with a 3way demonstrative system, has been characterized as a person-oriented system, such that the proximal form indicates proximity to the speaker, the medial form indicates proximity to the listener, and the distal form indicates distance from both speaker and listener (Diessel, 2012a). In the case of the Spanish system, there has been controversy, with some semantic analyses characterising it as distance-oriented (e.g., Hottenroth, 1982; Kemmerer, 1999; Levinson, 2004), while others situate it among person-oriented systems (e.g., Alonso, 1968; Cifuentes- Honrubia, 1989; Eguren, 1999), or a combination of both (Jungbluth, 2003). As a distance-base system, all Spanish demonstratives would indicate relative distance from the speaker. The first aim of this study is to test these two semantic analyses of the Spanish demonstrative system experimentally. However, before turning to the empirical test, it is worth discussing another parallel between the Spanish and Japanese demonstrative systems: the use of demonstratives as fillers.

Table 1: Spanish demonstrative determiners and pronouns

\begin{tabular}{|c|c|c|c|c|c|}
\hline \multirow{2}{*}{ Form } & \multicolumn{3}{|c|}{ Singular } & \multicolumn{2}{c|}{ Plural } \\
\cline { 2 - 6 } & Feminine & Masculine & Neuter & Feminine & Masculine \\
\hline Proximal & Esta & Este & Esto & Estas & Estos \\
\hline
\end{tabular}




\begin{tabular}{|c|c|c|c|c|c|}
\cline { 5 - 6 } Medial & Esa & Ese & Eso & Esas & Esos \\
\hline Distal & Aquella & Aquel & Aquello & Aquellas & Aquellos \\
\hline
\end{tabular}

\section{Inconsistent results in the literature}

Jungbluth (2003) proposed an analysis of Spanish demonstratives that has received considerable attention in recent years (e.g., Levinson, 2018; Diessel \& Coventry, 2020; Rocca \& Wallentin, 2020; Shin et al., 2020; Peeters et al., 2021; Skilton \& Peeters, 2021), but which deviates from traditional distance-oriented vs person-oriented accounts. Jungbluth argues that when Spanish speakers engage in face-to-face conversation, they 'treat their shared conversational space as uniform. Everything inside the conversational dyad is treated as proximal without any further differentiation' (2003:19). More specifically, she argues that the proximal demonstrative 'este' is generally used for referents at any location inside the faceto-face dyad. Peeters et al. (2021) recently noted that Jungbluth's proposal is in stark contrast with the results of a psycholinguistics study by Coventry et al. (2008), which showed that Spanish demonstratives express the relative distance of the referent from the speaker, but are also sensitive to the listener's position.

Peeters et al. (2021) highlight the different sources of these two studies, with Jungbluth (2003) basing her account on naturalistic data, while Coventry et al. (2008) elicited demonstratives in a laboratory task. Jungbluth (2003) divided her analysis in three parts, characterizing 'face to face', 'face to back' and 'side by side' conversation, depending on the speaker's and listener's position, respectively. While Peeters et al. (2021) describe this work as an 'in depth analysis of the Spanish demonstrative system', in my opinion, it suffers from a fundamental shortcoming: Jungbluth's (2003) analysis of face-to-face, face-to-back and sideby-side conversation seems to be based on a single naturalistic example of each situation. In addition, the analysis of naturalistic face-to-face conversation (which runs counter to the results of Coventry et al. (2008), as Peeters et al. (2021) correctly point out) is based on a mis-analysis of the example in question.

The following exchange between a seller and a buyer at a market stall is the naturalistic example used by Jungbluth (2003) to support her view that Spanish proximal demonstratives are used to refer to any object inside the conversational dyad, without space considerations:

Table 2: Example 2 from Jungbluth (2003:20)

\begin{tabular}{|l|l|l|}
\hline Speaker & Utterance & Jungbluth's annotations \\
\hline Seller & $\begin{array}{l}\text { ¿Qué más quiere? } \\
\text { [What else do you want?] }\end{array}$ & $\begin{array}{l}\text { The market woman is surrounded by lots } \\
\text { of crates with different kinds of vegetable } \\
\text { and fruit. }\end{array}$ \\
\hline Buyer & $\begin{array}{l}\text { Las }(2 \text { sec.) } \text { estas (4 sec.). ¿Cómo se } \\
\text { Ilaman? Las lechugas. }\end{array}$ & $\begin{array}{l}\text { The customer refers to the lettuces with } \\
\text { 'estas' although they are nearer to the } \\
\text { woman and they belong to her. }\end{array}$ \\
\hline
\end{tabular}


[The (2 sec.), these (4 sec.). What's

their name? The lettuces.]

In Spanish, as in other languages such as Japanese, Korean and Mandarin Chinese, demonstrative forms have been grammaticalized as fillers (also known as hesitation markers, planners or filled pauses), which are equivalent to etymologically opaque fillers such ' $u h^{\prime}$ ' and 'um' in English (see Kouteva et al., 2019). More specifically, the proximal form 'este' is the most common hesitation marker in Spanish (Clark \& Fox Tree, 2002; Soler Arechalde, 2008; Graham, 2013, 2018; Stoesslein, 2014). The above example is a clear instance of a tip of the tongue effect: the speaker takes 2 seconds to produce the second word in the utterance, and then 4 seconds to produce the third word, to continue wondering out loud what is the name of the vegetable he has in mind. Despite these clear hesitation cues, Jungbluth (2003) analyses the use of 'estas' as a "true" proximal demonstrative (see the annotations in Table 2), concluding that Spanish speakers do not make spatial distinctions within the conversational dyad.

While a single example of any linguistic phenomena may not be worth so much attention, in this particular case, Peeters et al. (2021) dedicate more than three pages of their paper to the discussion of the seemingly incompatible results of Jungbluth (2003) and Coventry et al. (2008), providing a new analysis that reconciles these findings. Alternatively, I propose a much simpler and grammatically accurate explanation of these alleged discrepancies, which is that Jungbluth (2003) mis-analyzed fillers as proximal demonstratives in Spanish, which led her to wrongly conclude that Spanish speakers do not make space distinctions within the conversational dyad. The theoretical question that motivated Jungbluth's study therefore remains: is the Spanish demonstrative system person-oriented (i.e. sensitive to both the speaker's and the listener's positions) or distance-oriented (i.e. anchored on the speaker)?

The results of Coventry et al. (2008) do not entirely elucidate this question because the relative position of the referent and the listener were not fully crossed in their experimental design (i.e. the target object could be placed in 4 different locations along a table, whereas speaker and listener were sitting either on opposite ends of the table or side by side at the same end). The first aim of the present study was therefore to more accurately investigate the nature of the Spanish demonstrative system (i.e. distance oriented vs person oriented; see Diessel, 2005) by varying object and listener position parametrically.

A broader but related question that has somewhat polarized cross-linguistic research on demonstratives in recent years is whether speakers' choice of demonstrative form is based on their own peripersonal space (i.e. what is within the speaker's reach), or is interactive in nature (i.e. relative to both interlocutors and their ongoing activity; for arguments and empirical evidence supporting these two positions, see Coventry et al., 2008; Piwek et al., 2008; Diessel, 2014; Peeters et al., 2014; Peeters \& Ozurek, 2016; Rocca et al., 2018, 2019a; Caldano \& Coventry, 2019; Diessel \& Coventry, 2020; Reile et al., 2020; Shin et al., 2020; Stukenbrock, 2020; Skilton \& Peeters, 2021; Todisco et al., 2021a). The second aim of the present experiment was to investigate the degree to which demonstrative choice is sensitive to interactive factors (such as the listener's position) in adult native speakers of Spanish. 


\section{The Experiment}

\section{Methods}

\section{Participants}

51 participants were recruited through Prolific, a crowdsourcing platform. N was originally set to 50, but one of the participants timed out, so an extra participant was automatically recruited. Demographics were set to monolingual speakers of Spanish, who were Spanish nationals and currently residents in Spain.

\section{Materials and Procedure}

A series of 16 displays were created showing two people on opposite sides of a table (for a sample display, see Fig. 1). The speaker in each display represented the participant (labelled 'You' in Spanish) and the listener represented the participant's friend (labelled 'Her' in Spanish). The cover story for the task was that the participant was moving houses and asked a friend for help packing his things in boxes. In each trial, there were four different objects on the table, and the participant had to ask his friend to pass him one of the objects.

Participants were asked to request the object that they were looking at in each trial. The participant position was fixed across trials (right-most position on the table, or Position 1), whereas the target object position varied along the table (Positions 1-4, moving left-wise). The friend's position also varied across trials (Positions 1-4), resulting in a fully-crossed $4 \times 4$ design (Target position $\mathrm{x}$ Interlocutor position). Trial presentation was randomized individually.

The task required that participants selected one of three possible responses: 'este' (this one), 'ese' (that one) or 'aquel' (that one over there). The instructions highlighted that participants should treat the scene as an interactive scenario, and imagine what their choice would be in each trial. For other recent studies using an online demonstrative-choice task, see Rocca et al. (2019b), Rocca and Wallentin (2020) and Todisco et al. (2021b).

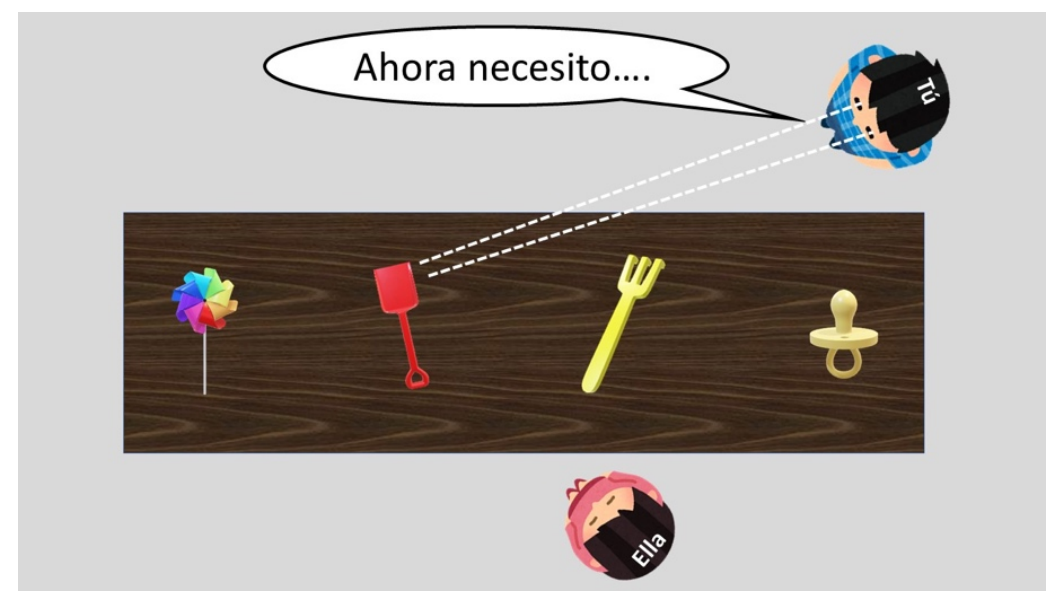

Fig. 1: Sample display from the task. The speaker represents the participant, who is asking a friend to pass him one of the objects on the table. The participant is always in Position 1 , whereas the positions of the target object and the friend vary across trials. In this instance, 
the friend is in Position 2, while the target is in Position 3. The speech bubble says 'Now I need...' in Spanish.

\section{Predictions}

According to the distance-oriented account of Spanish demonstratives, demonstrative choice is dictated by the relative distance of the referent from the speaker. Under this account, Object Position (relative to the speaker), but not Listener Position, should determine participants' responses.

According to the person-oriented account, Spanish proximal demonstratives (e.g., 'este') indicate proximity to the speaker, and would be unaffected by Listener Position. Thus, for Object Position 1 (i.e. when the referent is closest to the speaker) both theoretical accounts make the same predictions. However, under the person-oriented account, Spanish medial demonstratives (e.g., 'ese') indicate proximity to the listener. Thus, in Object Positions 2 and 3, participants' choice of 'ese' should be affected by both Object Position and Listener Position. Finally, distal demonstratives (e.g., 'aquel') indicate distance from both speaker and listener. Therefore, responses in Position 4 should also be sensitive to Listener Position (with participants choosing between 'ese' and 'aquel' depending on the listener's proximity to the target object).

\section{Results}

Descriptive statistics are plotted on Figs. 2-5. The clearest pattern of results emerging from this task is that participants show a ceiling preference for the proximal form 'este' when the target object is in Position 1 (i.e. closest to the speaker), regardless of the listener's position. By contrast, there seems to be more variability in participants' choice of the medial form 'ese' and the distal form 'aquel' depending on the listener's position.

\section{Proximal zone (Object Position 1)}

Using logistic mixed effects regression, the binary outcome variable of Proximal Demonstrative choice ('ESTE' = 1, 'ESE' and 'AQUEL' $=0$ ) was modelled for Object Position 1 (or proximal zone), with Listener Position (1-4) as a continuous predictor variable. All analyses were run using R statistical software (R Core Team, 2019) and all models were fit with the maximal random effect structure for Participants and Items (Barr, 2013).

As predicted by both theoretical accounts, Listener Position did not have a significant effect on the use of the proximal demonstrative 'este' in Object Position 1 ( $\beta=1.133$; SE = 1.033; $p=0.2726$; see Fig. 2). 


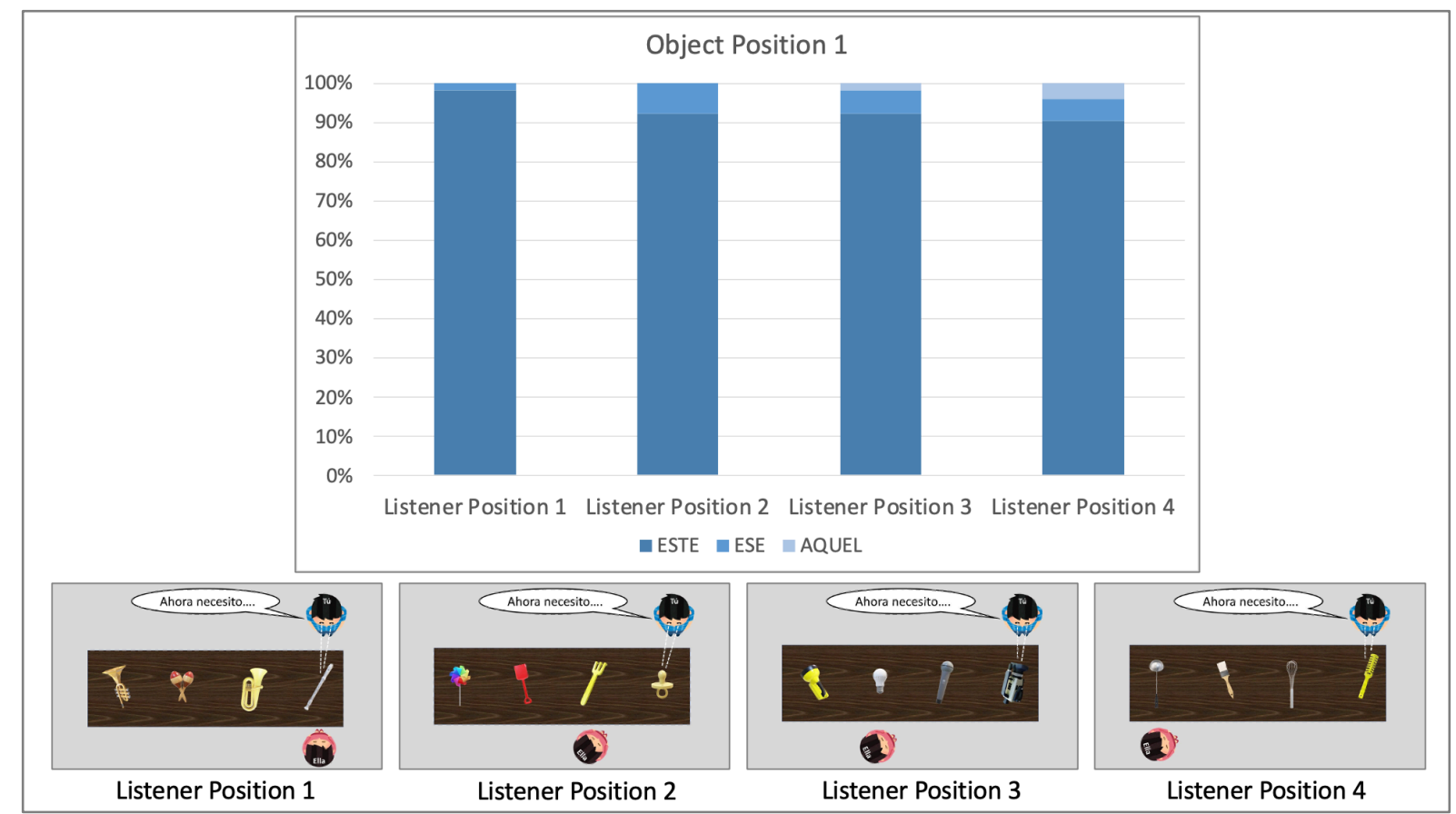

Fig. 2: Average percentage of demonstrative choice in each listener position when the target object was in Position 1.

\section{Medial zone (Object Positions 2 and 3)}

Using logistic mixed effects regression, the binary outcome variable of Medial Demonstrative choice ('ESE' = 1, 'ESTE' and 'AQUEL' =0) was modelled for Object Positions 2 and 3 (or medial zone), with Listener Position (1-4) and Object Position (2-3) as continuous predictor variables.

As predicted by both the distance-oriented and person-oriented accounts, Object Position had a significant effect on the use of the medial demonstrative 'ese', which increased from Position 2 to $3(\beta=-2.846$; $S E=0.9634 ; p<0.0032)$. Only supporting the predictions of the person-oriented account, Listener Position also had a significant effect $(\beta=$ -3.3329; $\mathrm{SE}=1.0083 ; p<0.0010)$, with the use of 'ese' increasing across Positions 1-4. Finally, there was a significant Object Position $x$ Listener Position interaction $(\beta=1.5716$; $\mathrm{SE}=$ $0.4540 ; p<0.0006)$.

To follow up on the interaction, Medial Demonstrative choice was modelled separately in Object Position 2 and Object Position 3, with Listener Position (1-4) as a continuous predictor variable (see Figs. 3 and 4). The effect of Listener Position was not significant in Object Position $2(\beta=-0.1856 ; \mathrm{SE}=0.1948 ; p=0.3407)$, but was significant in Object Position 3 ( $\beta=1.3549$; $\mathrm{SE}=0.3950 ; p<0.0007$ ), with the use of the medial demonstrative 'ese' increasing as the listener was closer to the referent. 


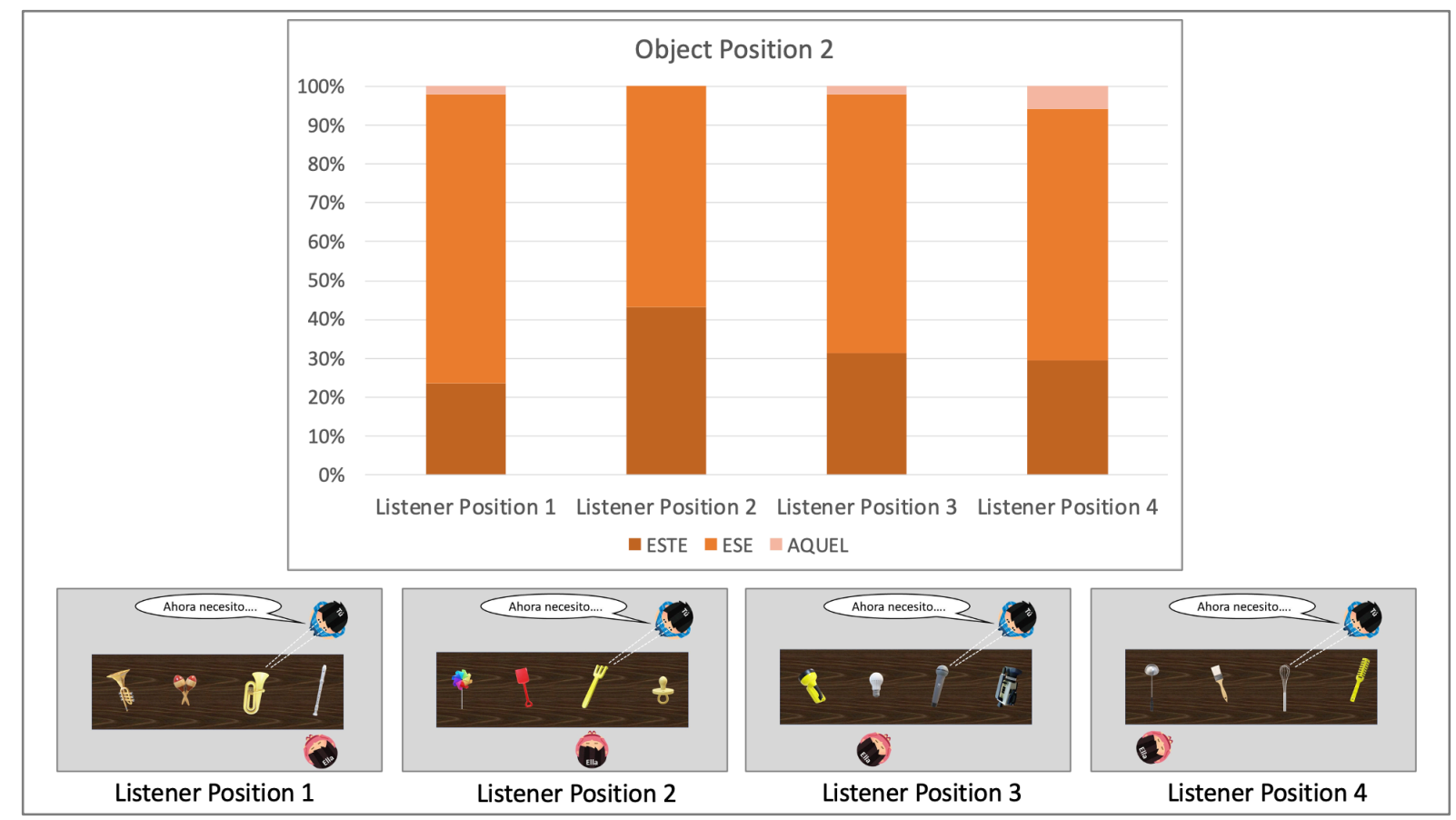

Fig. 3: Average percentage of demonstrative choice in each listener position when the target object was in Position 2.

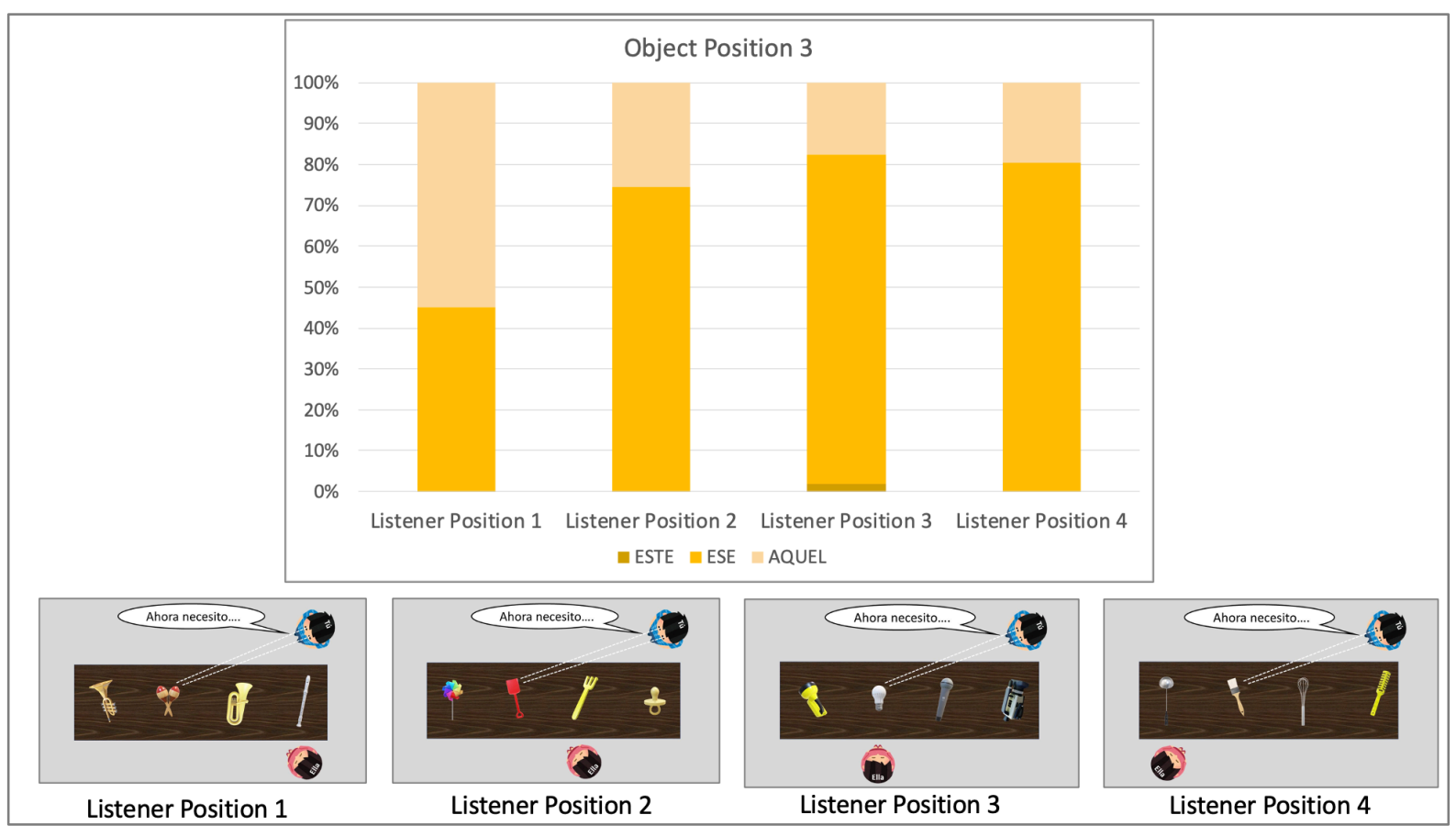

Fig. 4: Average percentage of demonstrative choice in each listener position when the target object was in Position 3.

\section{Distal zone (Object Position 4)}

Using logistic mixed effects regression, the binary outcome variable of Distal Demonstrative choice ('AQUEL' = 1, 'ESTE' and 'ESE' = 0) was modelled for Object Position 4 (or distal zone), with Listener Position (1-4) as a continuous predictor variable. Supporting the predictions of the person-oriented account, Listener Position had a significant effect on participant's use of 
'aquel' ( $\beta=-1.2271 ; \mathrm{SE}=0.2495 ; p<0.0001)$, which decreased when the listener was closer to the referent (see Fig. 5).

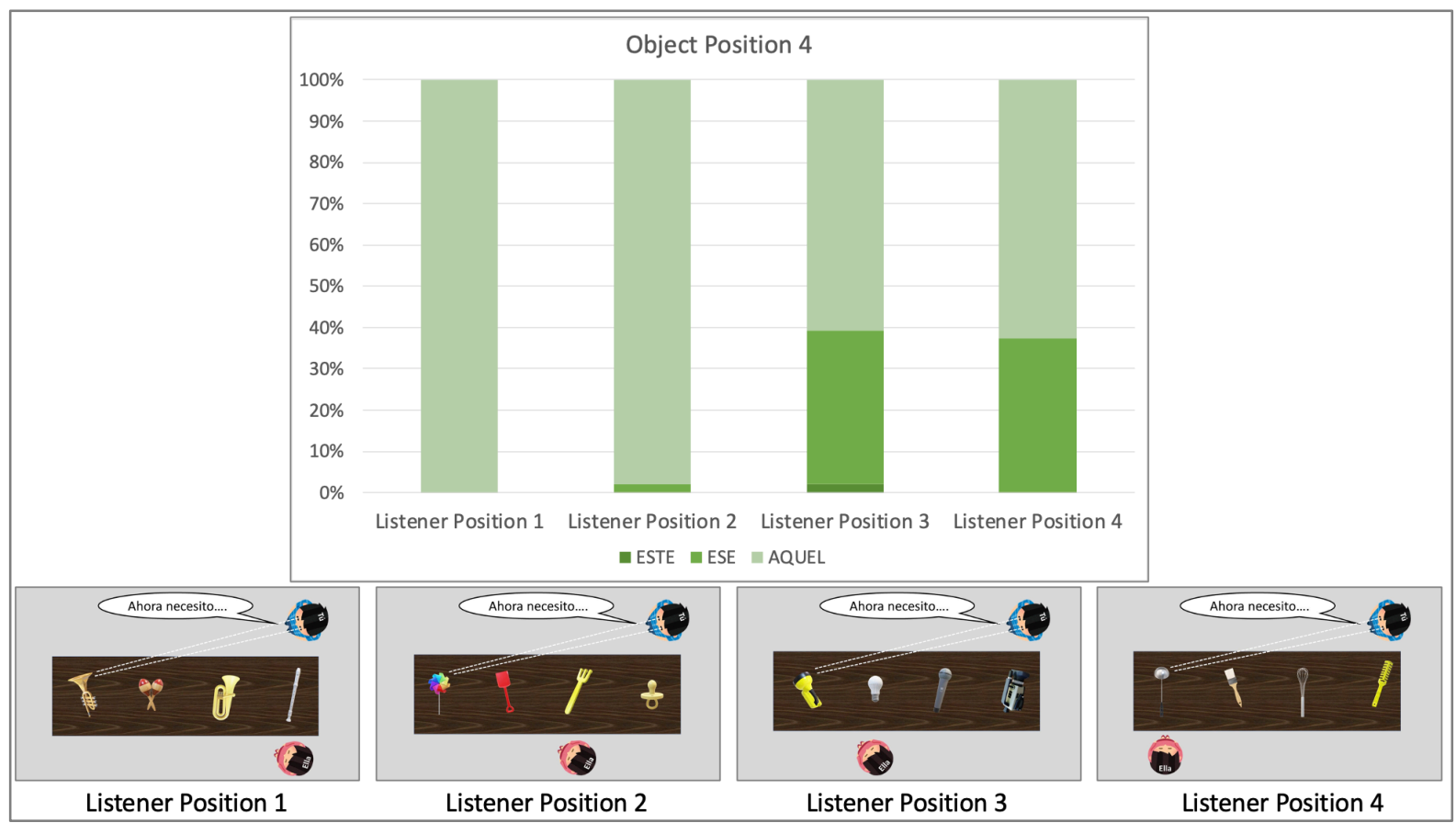

Fig. 5: Average percentage of demonstrative choice in each listener position when the target object was in Position 4.

\section{Discussion}

The results of this study strongly supported the person-oriented view of Spanish demonstratives, with the proximal form 'este' indicating proximity to the speaker, the medial form 'ese' indicating proximity to the listener, and the distal form 'aquel' indicating distance from both the speaker and the listener (for other person-oriented systems, see Diessel, 2005).

Regarding the egocentric vs interactive debate, the results were more mixed, with listener position affecting demonstrative choice only when the referent was two or three positions removed from the speaker. Seen this way, the results support Coventry et al.'s (2008) conclusion that there is a fundamental distinction between proximal and distal space from the speaker, which in the case of Spanish results in interactive effects only being observed in the more distal zones. However, once the referent is beyond the peripersonal space of the speaker, the interactive nature of demonstratives is clear in the Spanish system, also supporting the social account (Peeters et al., 2014, 2021; Peeters \& Ozyurek, 2016). Once the ongoing pandemic is resolved and testing in the lab can resume, future psycholinguistic studies should try to replicate these results in real-time interaction. For the moment, we are further exploring these questions online, but from a cross-linguistic perspective (Rubio-Fernandez \& Jara-Ettinger, in preparation).

Overall, the use of Spanish demonstratives supports the view that acquiring and using demonstratives can train spatial perspective taking (Rubio-Fernandez, 2020). Future crosslinguistic studies should also test this hypothesis from a developmental perspective (for a recent pilot study, see Shin \& Morford, 2020). Under this account, speakers of different 
languages need to automatize different relational values (e.g., distance or altitude of the referent) and different perspectives (e.g., the speaker's, the listener's or both) in their use of demonstratives, training in the process their social cognition through interactive communication.

\section{Acknowledgements}

This research was supported by a FRIPRO grant (\#275505) from the Research Council of Norway. The author gratefully acknowledges this funding. Thanks to Vrinda Bhatia, Madeleine Long and Vishakha Shukla for their useful feedback.

\section{Open practice statement}

Data and analysis script are available at the Open Science Framework repository (https://osf.io/tbrzi/?view only=410a92f8cdf840a4b62bea8b57c9e10d). The experiment was not preregistered.

\section{References}

Alonso, M. (1968). Gramatica del español contemporaneo. Madrid: Guadarrama.

Arechalde, M. Á. S. (2008). Algunos factores determinantes y contextos de uso para el marcador discursivo este... en el habla de la ciudad de México. Anuario de Letras. Lingüistica y Filología, 46, 155-168.

Bergqvist, H., \& Knuchel, D. (2019). Explorations of engagement: Introduction. Open Linguistics, 5(1), 650-665.

Caldano, M., \& Coventry, K. R. (2019). Spatial demonstratives and perceptual space: To reach or not to reach? Cognition, 191, 103989.

Cifuentes-Honrubia, J. L. (1989). Lengua y espacio: Introducción al problema de la deixis en español. Alicante: Universidad de Alicante.

Clark, E.V. 1978. From gesture to word: On the natural history of deixis in language acquisition. In J.S. Bruner and A. Garton (Eds.), Human Growth and Development (pp. 85120). Oxford: Oxford University Press.

Clark, H. H., \& Tree, J. E. F. (2002). Using uh and um in spontaneous speaking. Cognition, 84(1), 73-111.

Coventry, K. R., Valdés, B., Castillo, A., \& Guijarro-Fuentes, P. (2008). Language within your reach: Near-far perceptual space and spatial demonstratives. Cognition, 108(3), 889-895.

Diessel, H., \& Coventry, K. R. (2020). Demonstratives in spatial language and social interaction: An interdisciplinary review. Frontiers in Psychology, 11.

Diessel, H. (1999). The morphosyntax of demonstratives in synchrony and diachrony. Linguistic Typology, 3(1), 1-49.

Diessel, H. (2003). The relationship between demonstratives and interrogatives. Studies in Language, 27(3), 635-655 
Diessel, H. (2005). Distance contrasts in demonstratives. In M. Haspelmath, M. Dryer, D. Gil, \& B. Comrie (Eds.), World atlas of language structures (pp. 170-173). Oxford: Oxford University Press.

Diessel, H. (2006). Demonstratives, joint attention, and the evolution of grammar. Cognitive Linguistics, 17, 463-489.

Diessel, H. (2012a). Deixis and demonstratives. In C. Maienborn, K. v. Heusinger and P. Portner (Eds.), An international handbook of natural language meaning (pp. 1-25). Berlin: Mouton de Gruyter.

Diessel, H. (2012b). Buehler's two-field theory of pointing and naming and the deictic origins of grammatical morphemes. In T. Breban, L. Brems, K. Davidse and T. Mortelmans (Eds.), New perspectives on grammaticalization: Theoretical understanding and empirical description (pp. 35-48). Amsterdam: John Benjamins.

Diessel, H. (2014). Demonstratives, frames of reference, and semantic universals of space. Language and Linguistics Compass, 8(3), 116-132.

Eguren, L. J. (1999). Pronombres y adverbios demonstrativos. Las relaciones deícticas. In I. Bosque and V. Demonte (Eds.), Gramática Descriptiva de la Lengua Española (Vol. 1, pp. 929-974). Madrid: Espasa.

Evans, N., Bergqvist, H., \& San Roque, L. (2018a). The grammar of engagement I: Framework and initial exemplification. Language and Cognition, 10(1), 110-140.

Evans, N., Bergqvist, H., \& San Roque, L. (2018b). The grammar of engagement II: Typology and diachrony. Language and Cognition, 10(1), 141-170.

Graham, L. A. (2013). Comparing hesitation markers in Sanjuanero Spanish. Diálago de la Lengua, 5, 66-77.

Graham, L. A. (2018). Variation in hesitation: The case of este vs. eh in Latin American Spanish. Spanish in Context, 15(1), 1-26.

Hottenroth, P. M. (1982). The system of local deixis in Spanish. In J. Weissenborn and W. Klein (Eds.), Here and There: Crosslinguistic Studies on Deixis and Demonstration (pp. 133154). Amsterdam: John Benjamins.

Jungbluth, K. (2003). Deictics in the conversational dyad. In F. Lenz (Ed.), Deictic conceptualisation of space, time and person (pp. 13-40). Amsterdam, The Netherlands: John Benjamins Publishing.

Kemmerer, D. (1999). "Near" and "far" in language and perception. Cognition, 73(1), 35-63.

Kita, S. (Ed.). (2003). Pointing: Where language, culture, and cognition meet. Psychology Press.

Kouteva, T., Heine, B., Hong, B., Long, H., Narrog, H., \& Rhee, S. (2019). World lexicon of grammaticalization. Cambridge: Cambridge University Press.

Levinson, S. C. (2004). Deixis and pragmatics. In L. Horn and G. Ward (Eds.), The Handbook of Pragmatics (pp. 97-121). Oxford: Blackwell.

Levinson, S. C. (2018). Demonstratives: Patterns in diversity. Introduction to M. J. Dunn, N. J. Enfield, S. Cutfield, S. C. Levinson, and S. Meira (Eds.), Demonstratives in cross-linguistic perspective (pp. 1-42). Cambridge: Cambridge University Press. 
Peeters, D., \& Özyürek, A. (2016). This and that revisited: A social and multimodal approach to spatial demonstratives. Frontiers in Psychology, 7, 222.

Peeters, D., Azar, Z., \& Ozyurek, A. (2014). The interplay between joint attention, physical proximity, and pointing gesture in demonstrative choice. In Proceedings of the 36th Annual Meeting of the Cognitive Science Society (pp. 1144-1149).

Peeters, D., Krahmer, E., \& Maes, A. (2020). A conceptual framework for the study of demonstrative reference. Psychonomic Bulletin \& Review, 1-25.

Piwek, P., Beun, R. J., \& Cremers, A. (2008). 'Proximal' and 'distal' in language and cognition: Evidence from deictic demonstratives in Dutch. Journal of Pragmatics, 40, 694-718.

Reile, M., Plado, H., Gudde, H. B., \& Coventry, K. R. (2020). Demonstratives as spatial deictics or something more? Evidence from Common Estonian and Võro. Folia Linguistica, 54(1), 167-195.

Rocca, R., Tylén, K., \& Wallentin, M. (2019b). This shoe, that tiger: Semantic properties reflecting manual affordances of the referent modulate demonstrative use. PloS one, 14(1), e0210333.

Rocca, R., \& Wallentin, M. (2020). Demonstrative reference and semantic space: A large-scale demonstrative choice task study. Frontiers in psychology, 11, 629.

Rocca, R., Wallentin, M., Vesper, C., \& Tylén, K. (2018). This and that back in context: Grounding demon- strative reference in manual and social affordances. In Proceedings of the 40th Annual Meeting of the Cognitive Science Society (pp. 1522-1527).

Rocca, R., Wallentin, M., Vesper, C., \& Tylén, K. (2019a). This is for you: Social modulations of proximal versus distal space in collaborative interaction. Scientific Reports, 9, 14967.

Rubio-Fernandez, P., \& Jara-Ettinger, J. (in preparation). Evolutionary pragmatics and the origins of intersubjectivity.

Rubio-Fernandez, P. (2020). Pragmatic markers: The missing link between language and theory of mind. Synthese, 1-34. Invited contribution to the Special Issue The cultural origins of human social cognition.

Skilton, A. H., \& Peeters, D. (2021). Cross-linguistic differences in demonstrative systems: Comparing spatial and non-spatial influences on demonstrative use in Ticuna and Dutch. Journal of Pragmatics, 180, 248-265.

Shin, N., Hinojosa-Cantú, L., Shaffer, B., \& Morford, J. P. (2020). Demonstratives as indicators of interactional focus: Spatial and social dimensions of Spanish esta and esa. Cognitive Linguistics, 1.

Shin, N. L., \& Morford, J. P. (2020). Demonstratives in Spanish: Children's developing conceptualization of interactive space. In J. J. Colomina-Almiñana and S. Sessarego (Eds.), Language Patterns in Spanish and Beyond (pp. 285-301). Routledge.

Stoesslein, H. E. (2014). Los marcadores del discurso más frecuentes en el castellano argentino. Ибероамериканские тетради, 2, 138-146.

Stukenbrock, A. (2020). Deixis, meta-perceptive gaze practices, and the interactional achievement of joint attention. Frontiers in Psychology, 11, 1779. 
Todisco, E., Guijarro-Fuentes, P., Collier, J., \& Coventry, K. R. (2021a). The temporal dynamics of deictic communication. First Language, 41(2), 154-178.

Todisco, E., Rocca, R., \& Wallentin, M. (2021b). The Semantics of Spatial Demonstratives in Spanish: A Demonstrative Choice Task Study. Pre-print available at https://psyarxiv.com/uvkre/

Wellman, H. M. (2014). Making minds: How theory of mind develops. Oxford: Oxford University Press. 